\title{
Penerapan Arsitektur Metafora pada Pasar Festival INDUSTRI KREATIF DI KABUPATEN KLATEN
}

\author{
Hadinar Rizky $\mathbf{M}^{1 *}$, Musyawaroh ${ }^{2}$, Bambang Triratma ${ }^{3}$ \\ Program Studi Arsitektur, Fakultas Teknik, Universitas Sebelas Maret ${ }^{1}$ \\ E-mail : hadinarrizky@gmail.com* \\ Program Studi Arsitektur, Fakultas Teknik, Universitas Sebelas Maret ${ }^{2}$ \\ Program Studi Arsitektur, Fakultas Teknik, Universitas Sebelas Maret ${ }^{3}$
}

\begin{abstract}
Klaten Regency is located between big tourism cities, such as Surakarta and Yogyakarta. Klaten has its own potential of tourism and creative industries. At the other hand, the facility to support the development of creative industries in Klaten is not sufficient. The purpose of this design is to build a building that have complete facilities for creative industries sectors such as culinary, craft, fashion, music and performing art and not just for selling the products to costumer but also for the developing local creative micro to middle scope businessman in Klaten too, then the product could be developed dan known in national and international range. Using metaphor from one of the best and unique product of Klaten and response of the condition around the site would be a representation of iconic shape of Klaten Regency that would give a synergic interaction and could give a good response with the condition around the site.
\end{abstract}

Keywords: Architecture, Festival marketplace, Creative industry, Metaphor

\section{PENDAHULUAN}

Kabupaten Klaten terletak di antara dua daerah tujuan wisata nasional, yakni Yogyakarta dan Surakarta, sehingga memberikan potensi besar bagi Kabupaten Klaten untuk menjadi sebuah destinasi wisata. Posisi geografi Kabupaten Klaten juga sangat menguntungkan karena terletak di antara tiga kota yang mempunyai fungsi sebagai pusat budaya, pusat perdagangan, pusat pendidikan dan pusat pemerintah yaitu kota Yogyakarta, Semarang dan Solo, sehingga meningkatkan dinamika penduduk Klaten. (Perda Nomor 7 Tahun 2009 RPJPD KLATEN 2005-2025, hal. I-62)

Klaten merupakan salah satu kabupaten yang memiliki produk industri kreatif unggulan yang sudah diakui sebagai produk unggulan Jawa Tengah yakni kain tenun lurik Selain itu, produk-produk industri kreatif yang dihasilkan UMKM di Klaten beragam dan mempunyai potensi unggul seperti batik, keramik gerabah, dan lain sebagainya. Namun, hingga saat ini Klaten belum memiliki suatu wadah yang mampu menjadi pusat promosi, pemasaran dan pengembangan industri kreatif lokal.

Selain itu, saat ini pelaku UMKM di Kabupaten Klaten mengalami beberapa kesulitan di antaranya lemah pada aspek administrasi (pembukuan dan kelembagaan), kurangnya kesadaran para pelaku usaha untuk mendirikan koperasi, permodalan, keterbatasan networking dan akses pasar, kemampuan sumber daya manusia yang rendah terutama jiwa kewirausahaan dan profesionalisme sehingga berakibat banyak industri kreatif yang tergolong UMKM sulit berkembang dan ribuan usaha mikro kecil di Klaten hingga saat ini belum mengantongi ijin usaha mikro kecil.

Tujuan perancangan Pasar Festival Industri Kreatif ini yakni mendukung program pemerintah Kabupaten Klaten dengan menjadi pusat kegiatan perekonomian yang berisi pemusatan pemasaran produk-produk industri kreatif di Kabupaten Klaten yang tergolong UMKM, memberikan layanan, informasi dan advokasi kepada pelaku UMKM Klaten berkaitan dengan pengembangan usaha mulai 
dari hulu sampai hilir (bahan baku, processing, pemasaran), meningkatkan akses pelayanan pemberdayaan pelaku UMKM Kabupaten Klaten dalam bentuk destinasi wisata belanja, hiburan, dan kuliner serta edukasi yang mampu meningkatkan ekonomi masyarakat setempat dengan bantuan kegiatan festival yang telah menjadi kegiatan rutin Kabupaten Klaten.

Pasar Festival Industri Kreatif direncanakan sebagai bangunan komersil yang mampu menjadi ikon dengan menggunakan metafora dari produk unggulan Kabupaten Klaten dan respon terhadap lingkungan sekitar sehingga mengangkat citra lokal sosial dan budaya Kabupaten Klaten.

\section{METODE PERANCANGAN}

Metode perancangan Pasar Festival Industri Kreatif dimulai dengan mengidentifikasi pengguna dan kegiatan dari pasar festival dengan studi literatur. Berdasarkan studi literatur: Prinsip pasar festival merupakan campuran dari kios-kios toko penyewa lokal yang memiliki desain kios toko dan area umum yang mampu memberikan suatu energi pada ruang, dan memiliki ornamen arsitektur yang tidak rumit untuk menyoroti barang dagangan. (Maitland, 1990, hal. 25-26).

Pasar festival ditandai dengan kios-kios yang sama kelasnya, tidak ada kios utama (anchor tenant), dan dalam konsep seperti pameran dan festival dengan menggunakan unsur-unsur seperti panggung musik, kafe, plaza dan tempat untuk jalan-jalan. (Caves, 2005, hal. 179). Terdapat kios dan gerobak yang turut mengundang interaksi dengan konsumen dan terdapat penyewa ritel yang turut menjual produk mereka. (Caves, 2005, hal. 179).

Pasar festival menghubungkan ide modernis dari mall dengan kebutuhan postmodern untuk tontonan dengan perbedaan pasar festival dari mall yakni mereka memiliki konsep yang terbuka ke jalan atau tepi sungai dan kemiripan dengan mall yakni dalam cara menampilkan ruang publik sebagai simbolik kehidupan publik dimana tenaga kerja lokal dari kelas pekerja sebagai konsumen kelas menengah ke bawah berdampingan dengan kehidupan orang menengah ke atas. (Caves, 2005, hal. 179).
Berisi produk-produk lokal yang unik serta menghidupkan kembali interaksi antara pembeli dan penjual yang menjadi hal menarik dalam mengundang turis. (Bloom, 2004).

Menghasilkan prinsip-prinsip dalam membangun pasar festival yakni terdiri dari kios-kios lokal yang terdiri dari bangunan kios dan gerobak, ornamen tidak rumit untuk menyoroti barang dagangan, menyediakan ruang untuk pameran dan festival seperti penggunaan unsur panggung musik, kafe, plaza dan area umum lainnya, dan memiliki konsep bentuk sebagai ruang publik yang terbuka ke jalan.

Kemudian prinsip-prinsip tersebut dicapai dengan teori pendekatan Arsitektur Metafora yang dikaji terlebih dahulu lewat studi literatur. Arsitektur Metafora merupakan model budaya untuk menangkap pengalaman akan pengetahuan oleh individu dan kelompok sosial atau budaya, konsep yang kuat ini bahkan dapat diterapkan untuk nasionalisme, sebagai kombinasi dari sosial, sejarah, budaya, bahasa dan parameter wilayah. (Ungerer \& Schmid, 1996, hal. 120) dalam (Mansilla, 2003, hal. 37).

Arsitektur Metafora dapat diidentifikasikan ke dalam tiga kategori, yakni sebagai berikut Metafora abstrak (intangibel metaphor), metafora menjadi dasar kemunculan konsep, ide, kondisi manusia, atau kualitas tertentu (individualitas, kealamian, masyarakat, tradisi, budaya). Metafora konkrit (tangible metaphor), metafora menjadi dasar penciptaan suatu bentuk dengan tegas dari beberapa karakter visual atau materi. Metafora kombinasi (combined metaphor), terdapat gabungan antara konseptual dan visual sebagai awal terjadinya bentuk, menggunakan visual untuk mendeteksi unsur kualitas dan dasar-dasar suatu subjek. (Antoniades, 1990, hal. 30-31).

Selain itu, metafora merupakan terwujudnya bentuk bangunan dengan kemiripan secara visual dengan bentuk yang lain dengan pesan yang terkandung, termasuk semua bentuk dan rasa yang pernah dialami seperti warna, bentuk, tekstur, dan suara. (Lakoff \& Johnson, 2003, hal. 235). 
Kemudian dari teori yang digunakan terkait Arsitektur Metafora tersebut menghasilkan strategi desain perancangan Pasar Festival Industri Kreatif di Kabupaten Klaten. Objek yang dimetaforakan adalah produk unggulan UMKM Klaten sebagai perwujudan unsur sosial budaya, sejarah, bahasa dan parameter wilayah Kabupaten Klaten. Metafora akan diterapkan pada:

- Tapak

Meliputi pemilihan tapak yang mampu mewakili sosial budaya, bahasa, sejarah dan parameter wilayah dan sirkulasi pada tapak yang menghindarkan pengunjung dari kebosanan.

- Massa

Penerapan Arsitektur Metafora pada tata massa bangunan, bentuk bangunan dan tampilan bangunan terkait bentuk dan karakteristik yang menarik, dinamis, variatif sebagai inspirasi dalam proses desain sehingga dapat mengkomunikasikan fungsi bangunan dan memperoleh bentuk dan tampilan yang ekspresif.

\section{- Komplementer}

Menggunakan Arsitektur Metafora untuk mendukung bentuk yang dirancang sehingga dapat menghasilkan arsitektur yang lebih ekspresif dengan penerapan pada struktur dan material bangunan.

Kemudian pada aspek lain akan mempertimbangkan tercapainya interaksi sinergis yakni pencapaian pada tapak, orientasi dan view tapak, kebisingan pada tapak, vegetasi pada tapak, pengguna dan kegiatan, kebutuhan ruang, pola hubungan ruang, besaran ruang, dan utilitas bangunan.

\section{HASIL DAN PEMBAHASAN}

\subsection{Pengguna dan Peruangan}

Pengguna Pasar Festival Industri Kreatif terdiri dari Pelaku Industri kreatif, yang terdiri dari Pelaku UMKM sektor industri kreatif di bidang kuliner, mode, dan kerajinan, seniman Kabupaten Klaten sebagai pelaku seni pertunjukan dan festival dan tentor.

Pengunjung yang berasal dari masyarakat sekitar, wisatawan domestik dan mancanegara, dan terdiri dari konsumen produk UMKM, penonton pertunjukan seni dan festival, penonton galeri pameran industri kreatif, pembeli produk UMKM, peserta diskusi dan workshop kreatif mengenai UMKM dan seni.

Pengelola, yang terdiri dari direktur utama, direktur operasional dan pemasaran, direktur keuangan dan umum, sekretaris umum, Dinkop \& UMKM Bidang Pemberdayaan UMKM serta divisi dan staff.

Servis, yang terdiri dari staff kebersihan, keamanan dan teknisi.

\section{Kebutuhan dan besaran ruang.}

Pasar Festival Industri Kreatif diharapkan menjadi wahana stimulan bagi pelaku UMKM industri kreatif sehingga selain mewadahi pengembangan organisasional UMKM bangunan ini menyediakan area stimulan yang akan mendatangkan pengunjung sehingga tercipta interaksi yang sinergis antara keduanya. Kemudian dari dua area tersebut muncul ruang persinggungan antara keduanya yang nantinya dapat dimanfaatkan baik bagi pengunjung maupun pelaku UMKM industri kreatif.

Berdasarkan literatur dan studi preseden maka dapat diketahui kebutuhan ruang. Kemudian, besaran ruang dihitung berdasarkan jumlah pemakai, kebutuhan flow berdasarkan jenis kegiatan dan standar perhitungan menghasilkan kebutuhan ruang sebagai berikut:

Tabel 1. Total Kebutuhan Ruang

\begin{tabular}{|l|l|}
\hline $\begin{array}{l}\text { Kelompok } \\
\text { Kegiatan }\end{array}$ & $\begin{array}{l}\text { Luas yang } \\
\text { Diperlukan }\left(\mathrm{m}^{2}\right)\end{array}$ \\
\hline \multicolumn{1}{|c|}{$(1)$} & \multicolumn{1}{|c|}{$(2)$} \\
\hline Transisi & $2997 \mathrm{~m}^{2}$ \\
\hline Penerima & $512 \mathrm{~m}^{2}$ \\
\hline Utama Stimulan & $2138 \mathrm{~m}^{2}$ \\
\hline $\begin{array}{l}\text { Utama } \\
\text { Persinggungan }\end{array}$ & $659 \mathrm{~m}^{2}$ \\
\hline $\begin{array}{l}\text { Utama UMKM } \\
\text { Organisasional }\end{array}$ & $258 \mathrm{~m}^{2}$ \\
\hline Pendukung & $524 \mathrm{~m}^{2}$ \\
\hline $\begin{array}{l}\text { Pengelola dan } \\
\text { Servis }\end{array}$ & $182 \mathrm{~m}^{2}$ \\
\hline Total & \multicolumn{1}{c|}{$7540 \mathrm{~m}^{2}$} \\
\hline
\end{tabular}




\subsection{Perancangan Tapak}

Pemilihan Tapak

Lokasi Kabupaten Klaten yang terletak di antara Yogyakarta dan Surakarta, terdapat jalan utama di Klaten yang dilewati menuju Yogyakarta atau Surakarta, yakni Jl. Diponegoro, Jl. Merbabu dan Jl. JogjaSolo, sehingga tapak terpilih berada di $\mathrm{Jl}$. Jogja-Solo dengan bentuk trapesium yang terletak pada tepi jalan simpang tiga dan berada di timur area Candi Prambanan.

Tapak terpilih karena sesuai dengan RTRW Kabupaten Klaten dan termasuk kategori PKL dengan potensi lingkungan yang tinggi jika digunakan sebagai bangunan Pasar Festival karena letaknya yang berada di kawasan wisata dan dekat dengan berbagai obyek wisata terkemuka seperti Candi Prambanan, Candi Plaosan, danl lain-lain, serta didukung dengan akses jalan yang merupakan jalan arteri primer, jalan lingkungan dan jalan lokal sehingga bangunan mudah dicapai dengan beragam kendaraan.

Kondisi dan luasan tapak terpilih mampu mendukung fungsi yakni dengan luasan $15.500 \mathrm{~m}^{2}$. Selain itu, pemilihan tapak juga berdasarkan teori metafora sebagai perwujudan nasionalisme, sebagai kombinasi dari sosial, sejarah, budaya, bahasa dan parameter wilayah, karena letaknya yang berbatasan langsung dengan D.I. Yogyakarta maka dapat menjadi metafora pintu gerbang menuju Kabupaten Klaten sehingga lebih menjelaskan batas antara kedua wilayah tersebut.

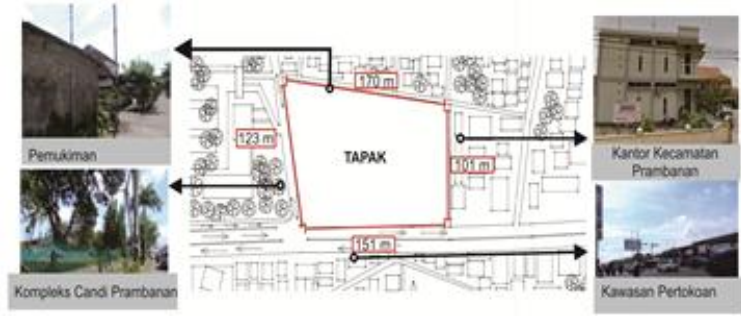

Gambar 1. Tapak Terpilih.

Pencapaian

Letak tapak yang berada di titik kemacetan mengakibatkan perlunya pemikiran yang matang dalam proses desain pencapaian bangunan, sehingga dalam menentukan letak Main Entrance dan Side Entrance agar memberikan interaksi sinergis antara lingkungan sekitar tapak dan bangunan Pasar Festival Industri Kreatif yang direncanakan berdasarkan potensi jalan di sekitar tapak, kemudahan untuk dikenali dan kemudahan untuk dicapai pengunjung, mampu menciptakan kelancaran lalu lintas, serta mendukung fungsi kegiatan sebagai pasar festival.

Terpilih main entrance di Jl. Jogja-Solo dan jalur keluar di Jl. Candi Sewu. Sedangkan side entrance di jalan desa Tlogo. Pada main entrance, untuk penanggulangan kemacetan yang sering terjadi di Jl. Candi Sewu dan Jl. Jogja-Solo maka pada kawasan Pasar festival didesain sebuah area transisi dan jalur lambat yang mampu menjadi alternatif bagi pengendara. Ketika terjadi kemacetan di Jl. Jogja Solo dari arah Jogja menuju Klaten dan pada Jl. Candi Sewu menuju Jl.Jogja-Solo, pengendara dapat memilih jalur lambat pada kawasan Pasar Festival yang ditandai dengan perbedaan material berupa batu candi agar tercipta interaksi sinergis dengan kondisi sekitar serta dirancang tanpa pembatas masif untuk terlihat lebih luas secara visual.

Untuk kemudahan pengunjung dan agar terciptanya interaksi sinergis dengan kawasan candi Prambanan maka disediakan jembatan penyeberangan orang (JPO) antara area parkir Candi Prambanan dengan area Pasar Festival Industri Kreatif dengan ketinggian 4,1 m.

View dan Orientasi

Letak tapak yang berada di tepi jalan menguntungkan bagi fungsi kegiatan dan pendekatan metafora yang dipilih agar tercipta interaksi sinergis antara bangunan dengan lingkungan di sekitar tapak, sehingga pemanfaatan view ke luar dan ke dalam bangunan difokuskan ke barat yang berupa area taman parkir Candi Prambanan dan selatan yang merupakan Jl. Jogja-Solo dan kawasan pertokoan. Bagian utara dan timur tapak tidak diprioritaskan karena merupakan area pemukiman dan perkantoran kecamatan Prambanan. 
Agar bangunan memberikan kenyamanan visual bagi pengamat maka memerhatikan jarak pandang manusia terhadap bangunan dengan penciptaan skyline yang berundak sehingga tidak menutupi jalan dan area Candi Prambanan, serta menyesuaikan alur pergerakan kendaraan di luar tapak yang kemudian memberikan tampilan visual yang atraktif dengan arsitektur metafora.

Sehingga karena letaknya di simpang tiga jalan, maka orientasi bangunan memiliki tiga muka agar metafora dapat dinikmati dari berbagai sisi dimana intensitas pengamat di setiap sisi tersebut tinggi. Tampilan bangunan difokuskan pula untuk ditonjolkan di tiga sisi bangunan yang merupakan jalan dan sudut dengan intensitas tinggi untuk dilalui dan diamati orang.

\section{Sirkulasi}

Sirkulasi di luar kawasan dan dalam kawasan Pasar Festival Indusri Kreatif di Kabupaten Klaten perlu menjadi fokus mengingat seringnya terjadi kemacetan maka desain alur sirkulasi harus mampu menghindari terjadinya kemacetan baru atau justru membantu mengurangi kemacetan yang sudah terjadi agar tercipta interaksi sinergis antara bangunan dan lingkungan sekitar.

Sirkulasi bagi pengelola dipisahkan dari pengunjung dengan memilih jalur alternatif di desa Tlogo dengan lebar jalan 3-4 $\mathrm{m}$ dan ketika keluar dari kawasan tidak harus lewat Jl. Candi Sewu namun dapat memilih jalan di desa Tlogo yang menuju Jl.Jogja-Solo.

Sirkulasi bagi pengunjung yang dimungkinkan datang dari tiga arah, yang pertama dari Jl. Jogja-Solo arah Klaten menuju Jogja maka dapat memanfaatkan lampu lalu lintas untuk berbelok ke kanan dan masuk ke jalur lambat Pasar Festival Industri Kreatif atau putar balik lewat lampu lalu lintas di Terminal Prambanan. Kedua, dari jalan Jogja-Solo arah Jogja menuju Klaten dapat langsung masuk ke jalur lambat Pasar Festival Industri Kreatif. Ketiga, dari Jl. Candi Sewu dapat memanfaatkan jalur lambat di barat kawasan Pasar Festival Industri Kreatif.

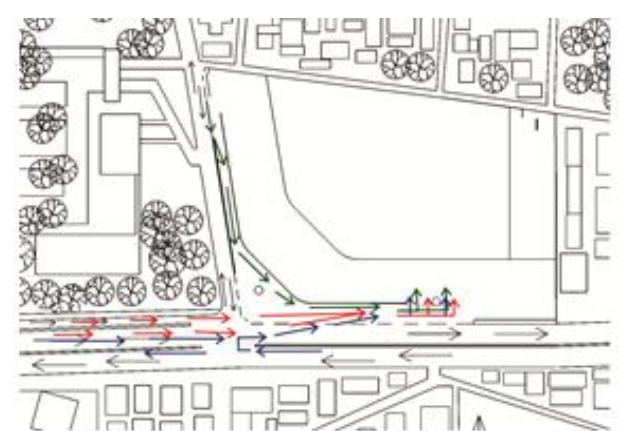

Gambar 2. Sirkulasi Menuju Tapak.

Kemudian sirkulasi di dalam kawasan membawa pengunjung langsung ke area taman parkir dan area drop off dan berujung ke jalur keluar kawasan.

Untuk sirkulasi di dalam bangunan mengambil filosofi motif hujan gerimis sehingga semakin masuk ke area bangunan akan semakin mendapatkan rezeki. Dengan konfigurasi jalur linear maka dari area parkir pengunjung akan menemui bangunan pendukung dan penerima kemudian masuk ke area kios dan galeri, setelah itu ke area utama yang menjadi stimulan yakni area kuliner dan panggung kreatif, kemudian jika lebih masuk lagi akan menemui UMKM mart dan perpustakaan mini untuk menambah wawasan pengunjung terhadap industri kreatif, kemudian sirkulasi berakhir di area UMKM organisasional untuk pengembangan pelaku UMKM.

\subsection{Perancangan Massa}

Prinsip-Prinsip Karakteristik Bangunan

Penerapan metafora lurik dan proses pembuatannya diharapkan mampu mendukung program pemerintah Kabupaten Klaten dalam menjadikan lurik sebagai ikon Klaten karena lokasi tapak yang mendukung sebagai metafora parameter wilayah karena berada di pintu gerbang ke Kabupaten Klaten.

Skyline bangunan yang berundak dengan dataran terendah pada simpang antara Jl. Jogja-Solo dan Jl.Candi Sewu sehingga menunjukkan keberadaan Candi Prambanan.

Bentuk Bangunan

Gubahan massa dasar dan komposisi massa bangunan Pasar Festival Industri 
Kreatif menggunakan inspirasi dari metafora proses pembuatan kain lurik dengan massa bangunan yang sesuai untuk fungsi kegiatan pasar festival industri kreatif yakni bentuk persegi yang efektif dan efisien bagi fungsi dan sesuai metafora yang dipilih dengan bentuk dasar untuk massa majemuk/ lebih dari satu massa.

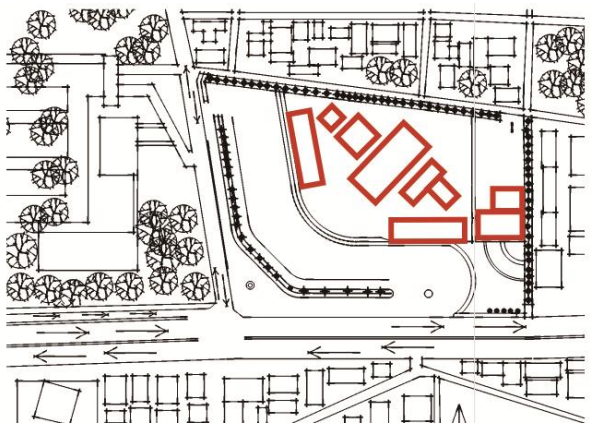

Gambar 2a. Bentuk Bangunan.

Tata Massa Bangunan

Konsep desain tata massa bangunan yang sesuai dengan peruntukan dan kegiatan pasar festival industri kreatif di Kabupaten Klaten agar pola kegiatan dapat terorganisir dengan nyaman dan memberikan interaksi yang sinergis dengan metafora motif lurik hujan gerimis sesuai dengan filosofinya.

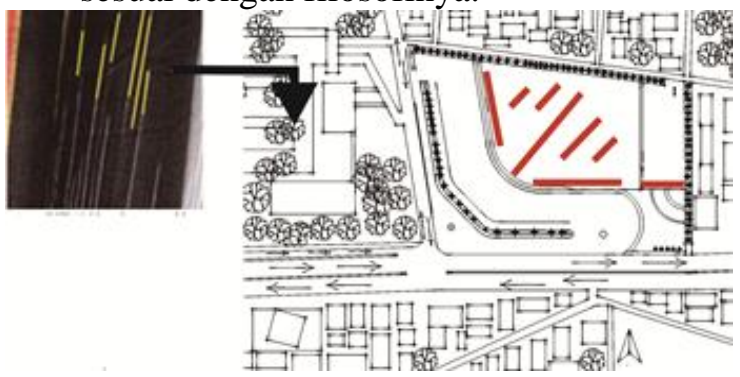

Gambar 3. Tata Massa dengan Metafora Motif Lurik

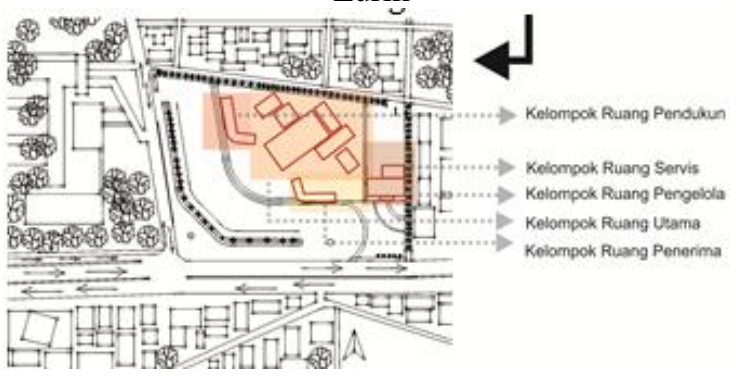

Gambar 4. Tata Massa Bangunan.

Tampilan Bangunan

Inspirasi dari alat tenun bukan mesin yang digunakan dalam proses membuat tenun lurik.
Metafora motif lurik Kluwung dengan filosofinya yakni sebagai tolak bala. (Djoemena, 2000), motif Sulur ringin dengan filosofinya yakni kehidupan yang langgeng. (Djoemena, 2000), motif Udan liris (Hujan gerimis) dengan filosofinya yakni kesejahteraan, harapan akan rezeki. (Djoemena, 2000), dan motif Tuluh watu dengan filosofinya yakni kekuatan dan keuletan yang biasa dipakai oleh pedagang di desa. (Djoemena, 2000)

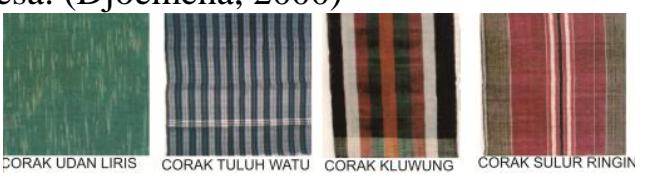

Gambar 5. Motif Kain Lurik

(Djoemena, 2000)

Agar tercipta interaksi sinergis dengan lingkungan sekitar, yakni letak tapak yang berdekatan dengan cagar budaya Candi Prambanan, maka bangunan yang direncanakan mengilhami bentuk berundak pada candi untuk diterapkan meskipun tidak secara serta merta sesuai dengan hasil keputusan desain sebelumnya, dilengkapi dengan menggunakan bahan material yang sesuai yakni batu candi dan batu alam.

Kronologi metafora:

Skyline Bangunan

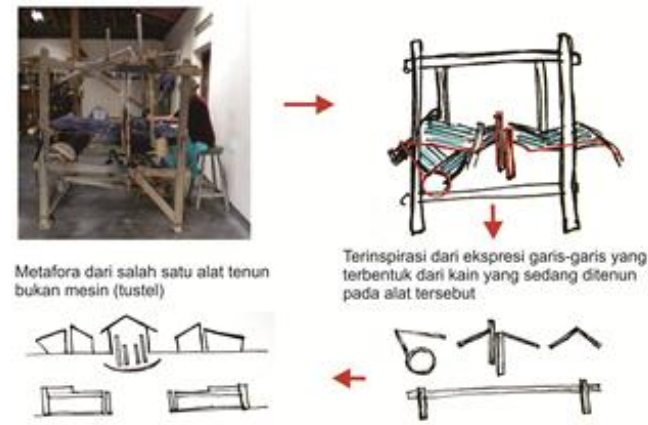

Gambar 6. Metafora ATBM.

Terinspirasi dari ekspresi garis-garis yang terbentuk dari kain yang sedang ditenun pada alat tustel tersebut dan sudut-sudut yang terbentuk yakni 10 dan 15 derajat menjadi inspirasi dalam membenuk atap bangunan. Dari skyline yang terbentuk maka menjadi dasar dalam mendesain tampilan bangunan dengan menambahkan unsur-unsur pembentuk tampilan bangunan seperti dinding, atap dan bukaan. Jarak antar 
bangunan yang terbentuk disesuaikan dengan kondisi tapak.

Selain itu skyline bangunan juga diperhatikan pada point interest yakni di persimpangan antara Jl. Jogja-Solo dan Jl. Candi Sewu dengan menerapkan bentuk berundak pada candi untuk dikombinasikan dengan bentuk alat tenun lurik dan motif lurik.
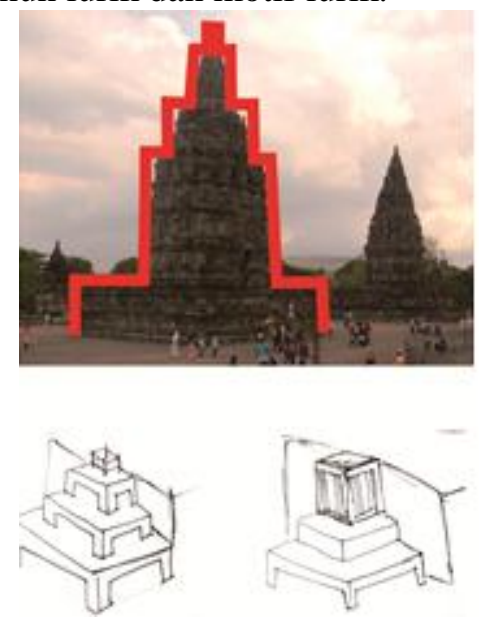

Gambar 7. Metafora Berundak pada Candi.

Terpilih alternatif skyline 1 dikarenakan bentuk lebih sesuai dengan bentuk candi dan memiliki potensi untuk dikombinasikan dengan metafora alat tenun lurik tustel dan motif kain lurik secara maksimal.

\section{Point of Interest Bangunan}

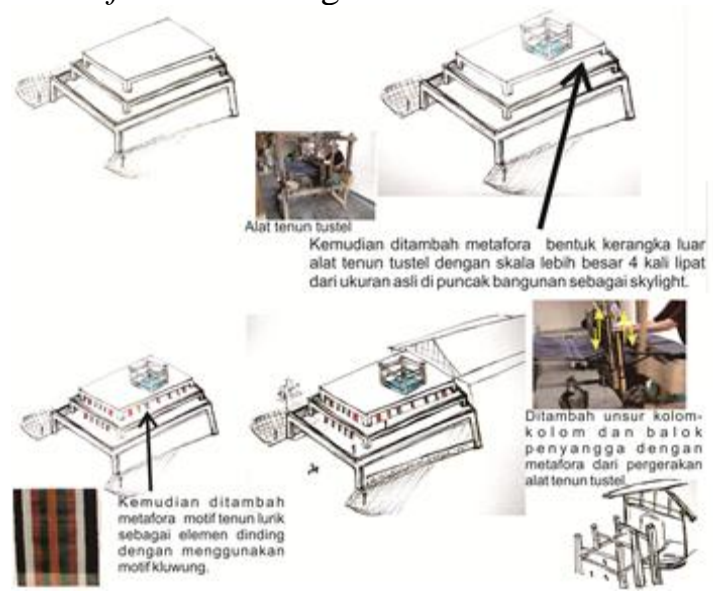

Gambar 8. Metafora pada Bangunan Utama.

Point of interest berupa area makan outdoor dengan inspirasi dari bentuk berundak pada candi. Kemudian ditambah metafora kain lurik motif kluwung sebagai elemen dinding dan kolom serta balok sebagai metafora dari pergerakan alat tenun tustel.
Elemen Tampilan Bangunan

Alat Sekir
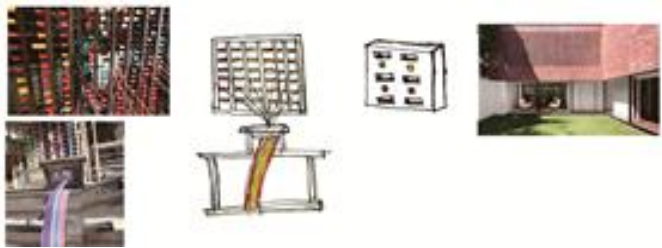

Gambar 9. Penerapan Metafora Alat Sekir.

Alat sekir menjadi inspirasi dalam merancang tampilan bangunan pada desain secondary skin berbentuk rooster dari batu bata.

Motif kain lurik yang sedang ditenun pada tustel menjadi inspirasi dalam merancang tampilan bangunan terutama pada desain secondary skin berbahan logam dengan teknik laser cutting.
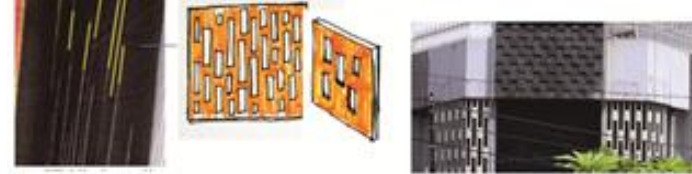

Gambar 10. Penerapan Motif Lurik.

3.3 Perancangan Komplementer

Struktur dan Material

Struktur dan material yang dipilih mampu mendukung bentuk bangunan serta utilitas yang mendukung fungsi bangunan. Sub Structure bangunan menggunaan pondasi batu kali pada bangunan berlantai satu dan footplat pada bangunan berlantai dua dan tiga. Pada upper structure bangunan, rigid frame pada seluruh bangunan dan struktur bentang lebar pada area stimulan kuliner. Pada super structure, genteng beton pada bangunan kios, persinggungan, organisasional dan pengelola. Genteng metal dan polycarbonate pada area bentang lebar. Pelat beton pada massa yang membutuhkan atap datar seperti pada area penerima, pendukung dan servis serta pada point of interest bangunan.

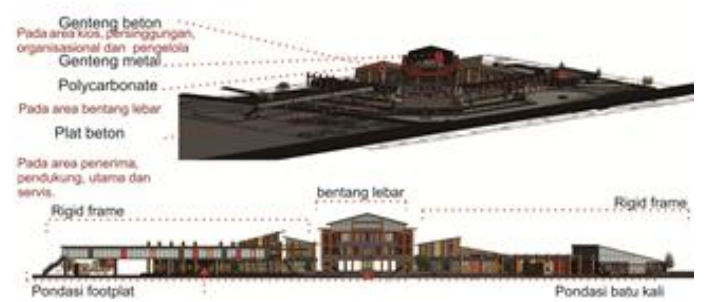

Gambar 11. Penggunaan Struktur dan Material. 


\section{Hasil Perancangan}

Pasar Festival Industri Kreatif di Kabupaten Klaten adalah sebuah wadah pusat perbelanjaan untuk sarana informasi, promosi dan pemasaran produk UMKM industri kreatif di bidang kerajinan, kuliner dan mode serta sebagai sarana pelatihan dan pengembangan kreatifitas pelaku UMKM di Kabupaten Klaten yang dikemas dalam wisata belanja, kuliner, dan hiburan serta edukasi yang terdapat kegiatan festival dari masyarakat lokal dan pelaku industri kreatif di bidang musik dan seni pertunjukan.

Nama Bangunan : Pasar Festival Industri Kreatif

Lokasi

Luas Lahan

Luas Bangunan

: Jl. Jogja-Solo

$: 15.500 \mathrm{~m}^{2}$

$: 7540 \mathrm{~m}^{2}$

Jumlah Lantai

: Terdiri dari massa bangunan 1 lantai, 2 lantai dan 3 lantai.
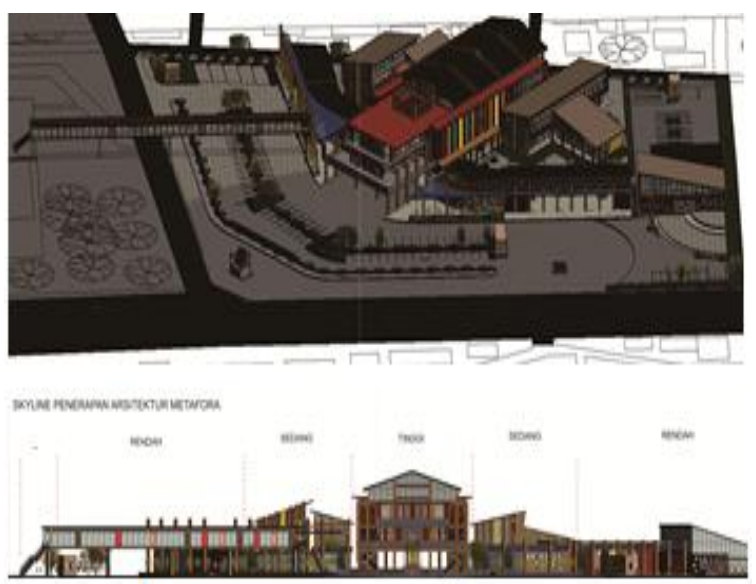

Gambar 12. Konsep Tampilan Bangunan

Konsep penggunaan dinding rooster dari batu alam yakni batu candi agar tercipta koneksi dengan bangunan di arah barat yakni candi Prambanan, selain itu sesuai dengan metafora parameter wilayah karena batu ini banyak ditemui di Klaten, penggunaan scuplture metafora tenun lurik serta secondary skin dari batu bata dan logam cutting bermotif lurik hujan gerimis, kluwung dan bentuk sekir dengan filosofi warna melengkapi tampilan bangunan.

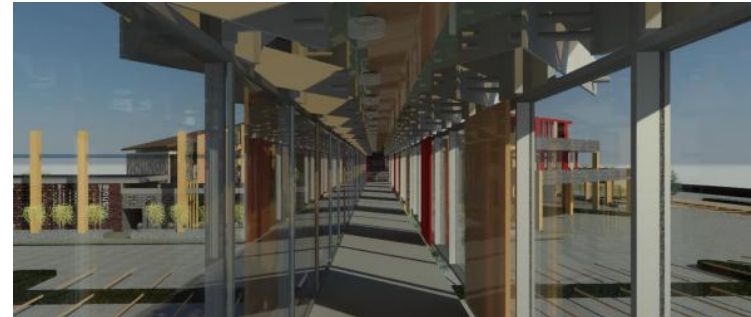

Gambar 13. Jembatan Penyeberangan Orang

Material pada JPO (Jembatan Penyeberangan Orang) didominasi kaca sebagai elemen transparan dan kenetralan karena menghubungkan dua bangunan dengan karakter berbeda. Selain itu agar ketka pengunjung menggunakan JPO (Jembatan Penyeberangan Orang) dapat mengamati metafora pada point of interest bangunan. Point of Interest bangunan menerapkan metafora kombinasi dari bentuk berundak candi dan motif lurik serta alat tenun. Metafora motif lurik yang dikombinasikan pada metafora berundak candi pada point of interest bangunan.

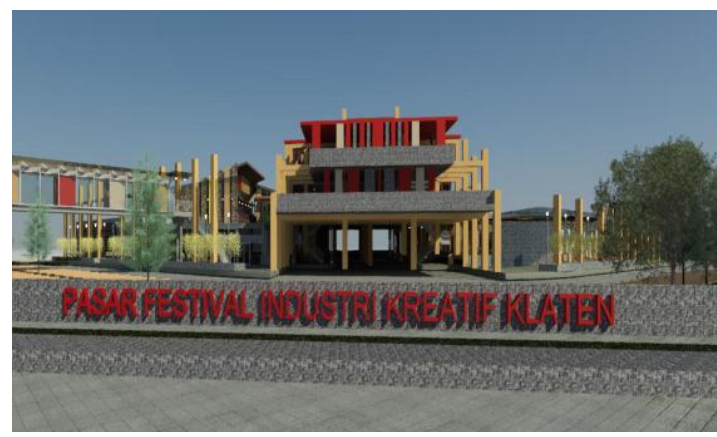

Gambar 14. Tampilan Bangunan Utama.

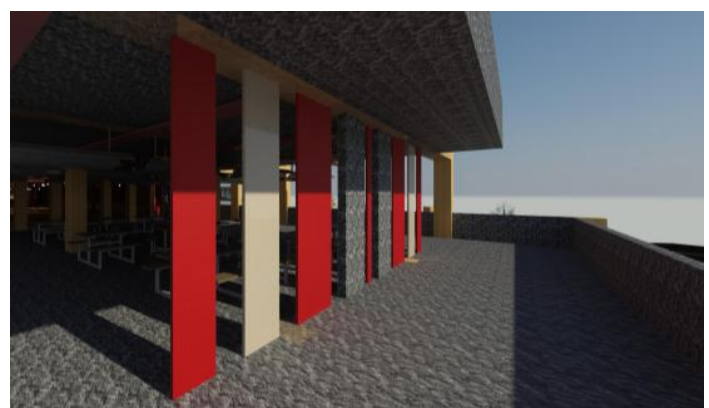

Gambar 15. Metafora pada Bangunan Utama. 


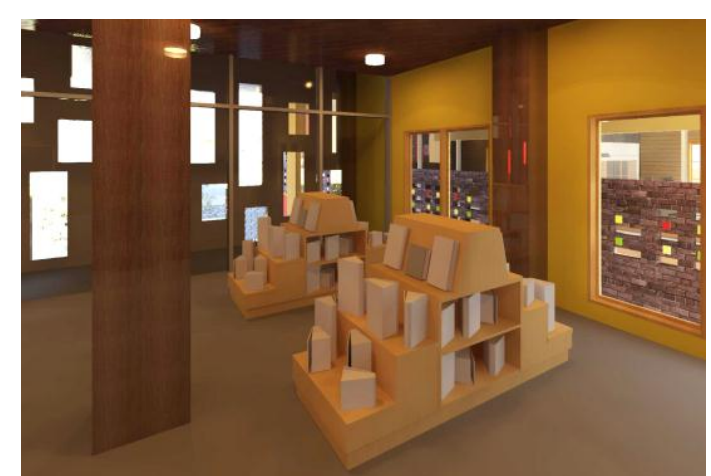

Gambar 16. Penerapan Motif Lurik Udan Liris.

Metafora motif lurik udan liris sebagai secondary skin menjadi elemen estetis dinding baik pada eksterior maupun interior. Penerapan metafora motif lurik pada plafon bangunan utama. Levelling pada area bangunan sebagai pencegah kebosanan dan mengilhami bentuk pada candi.

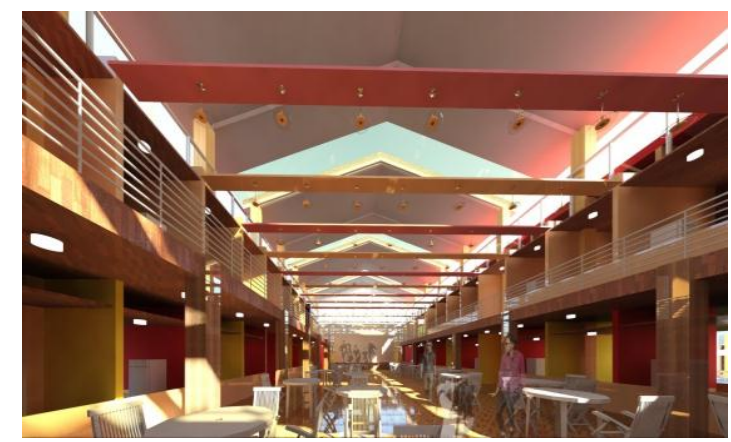

Gambar 17. Interior Bangunan Utama.

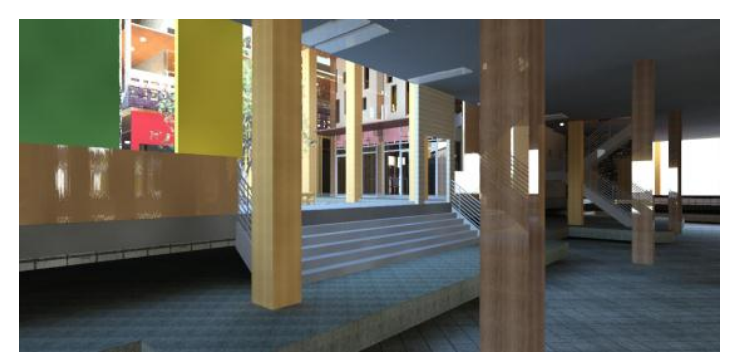

Gambar 18. Levelling pada Bangunan.

\section{KESIMPULAN}

Penerapan metafora dalam perancangan Pasar Festival Industri Kreatif di Kabupaten Klaten dalam prosesnya perlu untuk terlebih dahulu fokus pada suatu kegiatan yakni festival karena merupakan titik temu yang menjadi wahana stimulan antara pelaku UMKM dengan pengunjung dan konsumen yang kemudian dapat dijadikan sebagai pusat dalam menerapkan bentuk metafora yang sesuai dengan fungsi bangunan, sehingga fungsi utama bangunan mudah dikenali pengamat dan mampu menjadi point of interest dalam suatu bangunan.

Selain itu, kondisi sekitar tapak bangunan yang direncanakan juga perlu untuk diperhatikan dan dianalisis dalam proses desain, sehingga desain yang dihasilkan akan menimbulkan interaksi sinergis antara bangunan yang dirancang dengan lingkungan sekitar dengan menyelesaikan persoalan yang sudah ada atau yang akan ditimbulkan oleh bangunan yang direncanakan.

\section{REFERENSI}

Lakoff, G., \& Johnson, M. (2003). Metaphors We Live By. London: The university of Chicago press.

Antoniades, A. C. (1990). Poetic of Architecture: Theory of Design. New York: Van Nostrand Reinhold.

Bloom, N. D. (2004). Merchant of Illusion: James Rouse, America's Salesman of the Businessman's Utopia. Ohio: Ohio State University Press.

Caves, R. (2005). Encyclopedia of the City. London and New York: Taylor \& Francis Group.

Djoemena, N. S. (2000). Lurik: Garis-Garis Bertuah. Jakarta: Djambatan.

Maitland, B. (1990). The New Architecture of The Retail Mall. New York: Van Nostrand Reinhold.

Mansilla, P. U. (2003). Metaphor at work: a study of metaphors used by European architects when talking about their projects. Ibérica 5, 37.

Perda Nomor 7 Tahun 2009 RPJPD KLATEN 2005-2025. (n.d.). Retrieved from Sistem Informasi Tata Ruang: http://simtaru.klatenkab.go.id/ diakses tanggal 30/09/2016

Ungerer, F., \& Schmid, H.-J. (1996). An Introduction to Cognitive Linguistics. In P. U. Mansilla, Metaphor at work: a study of metaphors used by European architects when talking about their 
projects (p. 37). Madrid: Universidad Politécnica de Madrid.

Djoemena, N. S. (2000). Lurik: Garis-Garis Bertuah. Jakarta: Djambatan.

Perda Nomor 7 Tahun 2009 RPJPD KLATEN 2005-2025. (n.d.). Retrieved from Sistem Informasi Tata Ruang: http://simtaru.klatenkab.go.id/ diakses tanggal 30/09/2016. 